Received 00th January 20xx, Accepted 00th January 20xx DOI: $10.1039 / x 0 x \times 00000 x$

\title{
From a 1,2-Azaborinine to Large $B N$-PAHs via Electrophilic Cyclization: Synthesis, Characterization and Promising Optical Properties
}

\author{
Yannik Appiarius ${ }^{a}$, Tim Stauch $^{b}$, Enno Lork ${ }^{c}$, Pascal Rusch $^{d}$, Nadja C. Bigall ${ }^{d}$ and Anne Staubitz ${ }^{a *}$
}

\begin{abstract}
We present a convergent synthetic route towards boron-nitrogen containing polycyclic aromatic hydrocarbons ( $B N$-PAHs) that allowed us to synthesize six derivatives. Starting from the conjunction of a 1,2-azaborinine nucleophile and various aryl electrophiles, the key step was the extension of the aromatic system via an electrophilic ring closure of the respective alkyne precursors. Our route allows to circumvent the use of substituted PAH precursors, which are often unavailable. Instead, it builds up the $B N$-PAHs solely from easily accessible monocycles. All derivatives were emissive in solution and solid state with quantum yields up to $\Phi_{\text {lum }}=0.40$ and small Stokes shifts. The emission wavelengths in solid state were notably dependent on the connectivity of the rings. Due to excimer formation in one derivative, its emission was significantly redshifted with a comparatively slow secondary photoluminescence $(\mathrm{PL})$ decay.
\end{abstract}

\section{Introduction}

1,2-Azaborinines represent a class of six-membered heteroarenes, in which a $C C$ unit is formally replaced by a dipolar $B N$ unit, making them the isosteric and isoelectronic ${ }^{1,2}$ but less aromatic ${ }^{3-6}$ congeners of benzene. However, the imbalanced distribution of $\pi$-electrons ${ }^{7,8}$ causes notably divergent optoelectronic properties, which was demonstrated for several $B N$ containing materials including polymers. ${ }^{9-14}$

PAHs are characterized by planar, rigid and thermally stable backbones. ${ }^{15-17}$ Regarding their optoelectronic properties, large delocalized $\pi$-systems ${ }^{18,19}$ and $\pi$ - $\pi$-stacking ${ }^{20,21}$ often lead to a high charge carrier mobility. ${ }^{22,23}$ Moreover, fluorescence in the visible spectrum ${ }^{24,25}$ in $\mathrm{PAHs}$ such as pyrenes ${ }^{26,27}$ or perylene diimides ${ }^{28,29}$ made them widely used, semiconducting materials in organic electronics like organic light emitting diodes (OLEDs). ${ }^{30,31}$ Over the past decade, the incorporation of one or

\footnotetext{
a. University of Bremen, Institute for Analytical and Organic Chemistry,

Leobener Straße 7, D-28359 Bremen, Germany

MAPEX Center for Materials and Processes,

Bibliothekstraße 1, D-28359 Bremen, Germany, E-mail: staubitz@uni-bremen.de

b. University of Bremen, Institute for Physical and Theoretical Chemistry,

Leobener Straße 7, D-28359 Bremen, Germany;

Bremen Center for Computational Materials Science,

Am Fallturm 1, D-28359 Bremen, Germany;

MAPEX Center for Materials and Processes,

Bibliothekstraße 1, D-28359 Bremen, Germany

University of Bremen, Institute of Inorganic Chemistry and Crystallography,

Leobener Straße 7, D-28359 Bremen, Germany

d. Leibniz University Hannover, Institute for Physical Chemistry and

Electrochemistry, Callinstraße 3a, D-30167 Hannover, Germany

Cluster of Excellence PhoenixD (Photonics, Optics, and Engineering - Innovation Across Disciplines), Hannover, Germany.

† Electronic Supplementary Information (ESI) available: Experimental procedures, photophysical data, NMR spectra, single crystal data and additional calculations. See DOI: $10.1039 / \times 0 x x 00000 x$
}

more 1,2-azaborinine units into PAHs has gained increased interest because the resulting $B N-\mathrm{PAHs}$ feature several beneficial qualities: Compared to their $C C$ analogs, narrowed frontier molecular orbital gaps with particularly stabilized highest occupied molecular orbitals (HOMOs) ${ }^{32-35}$ as well as redshifted emission spectra ${ }^{36}$ could be observed. Moreover, quantum yields up to unity ${ }^{37,38}$ and hole mobilities up to $0.15 \mathrm{~cm}^{2} \mathrm{~V}^{-1} \mathrm{~s}^{-1} 39$ emphasize the application potential of $B N$-PAHs. At the same time, the $B N$ substitution did not induce significant thermal destabilization. ${ }^{35,40-42}$

The synthetic approach towards $B N$-PAHs highly depends on the desired position of the $B N$ unit in the target molecule. Most frequently, electrophilic borylations were performed with suitable (poly)aromatic amines, either with neighboring vinylor aryl-groups. ${ }^{32,43-46}$ This approach is generally simple to follow, high yielding, and it forms the $B N$ bond at a late stage. Moreover, metathesis reactions can be employed to build up new six-membered rings that include $B$ and $N$ heteroatoms. ${ }^{47,48}$

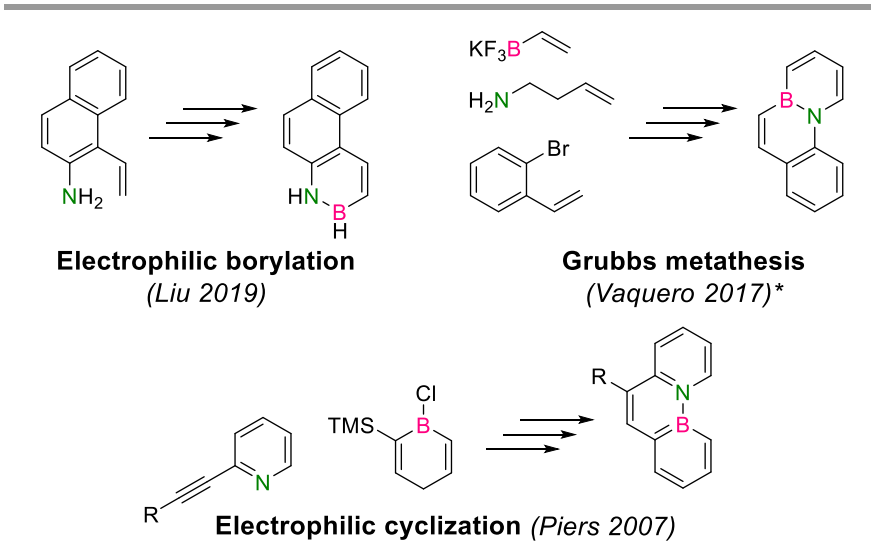

Scheme 1 Examples of recent approaches towards $B N$ phenanthrenes. *Also involves an electrophilic borylation. 
An innovative methodology was developed by Piers and coworkers, involving consecutive $B N$ bond formation and cycloisomerization of a boracycle and various ethynylpyridine precursors $^{49}$ (Scheme 1). Both reaction steps typically proceed at ambient temperature without the requirement for catalysts due to a strongly nucleophilic carbon atom $\alpha$ to boron. Only in case of $R=T M S$, the addition of platinum(II) chloride, $a$ commonly used soft metal catalyst for electrophilic cyclizations, ${ }^{50}$ was required.

This work and later also other reports ${ }^{44,51}$ impressively clarified the high impact of the position of the $B N$ heteroatoms on the optical properties of $B N$-PAHs. The influence of internally implemented $B N$ units was throughout much higher than the influence of $B N$ moieties in peripheral positions. ${ }^{37,52}$

Table 1 This approach, involving Suzuki-Miyaura cross-coupling, deprotection and electrophilic ring closure reactions. The table shows commercial precursors and the respective compounds as prepared in this work. ORTEP structures are shown at $50 \%$ probability under omission of hydrogen atoms.

transformations:
a) electr. halogenation
b) Sonogashira $\mathrm{CC}$
c) $\mathrm{N}$-acylation, cyclization,
hydrolysis, diazotization

Entry Starting Material Electrophilic Arene

2<smiles>Ic1ccsc1I</smiles>

3

3<smiles>Brc1cccnc1I</smiles>

4

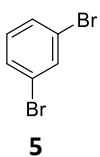<smiles>Brc1ccc(Br)c(Br)c1</smiles>

6

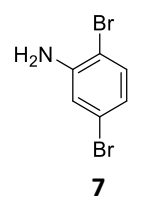<smiles>CSC#Cc1ccsc1Br</smiles>

9, $21 \%$ over 2 steps $(a, b)$<smiles>CC#Cc1cccnc1Br</smiles>

$10,77 \%$ over 1 step (b)
11, $49 \%$ over 2 steps $(a, b)$

12, $52 \%$ over 2 steps $(a, b)$<smiles>CC#Cc1c(Br)ccc(Br)c1C#CSC</smiles>

13, $5 \%$ over 5 steps $(c, b)$

\section{Cross-Coupled Product}

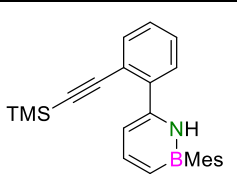

$14,82 \%$<smiles>C=C(Nc1ccccc1)c1sccc1C#CC</smiles><smiles>CC#Cc1cccnc1C1=CC=C[AsH]N1</smiles>

16, $71 \%$
Ring-Closed Product

Ring-Closed Product

BN-PAH1, 73\%

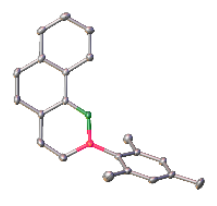

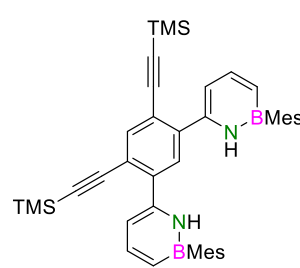

$17,89 \%$

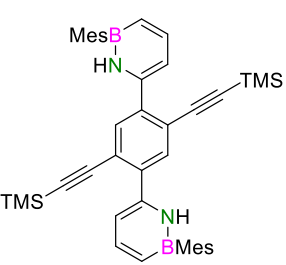

$18,39 \%$

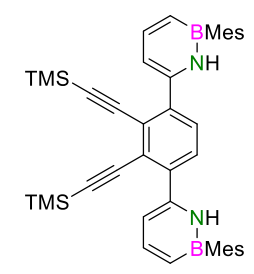

$19,73 \%$

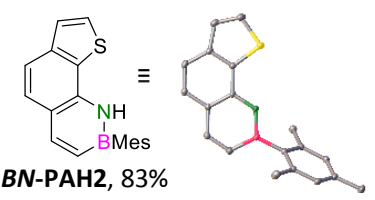<smiles>C[As]1C=Cc2ccc3cccnc3c2N1</smiles>

BN-PAH3, 49\% 
Most of the discussed routes follow a linear strategy: The entire series of precursors is fixed at the outset, depending on the desired product. However, the requirement for large and appropriately substituted PAH precursors can be difficult to meet, as the introduction of reactive groups into PAHs often favors only one regiochemistry and others can be impossible to access. ${ }^{53-55}$ Consequently, a lack of purchasable or preparable precursors leads to the methods' limitation to relatively small targets like phenanthrenes. However, the major benefits of extended PAHs are often not observable in these small systems.

We envisioned a convergent synthetic pathway that allows the construction of much larger systems, using the same 1,2-azaborinine precursor and conditions for all desired molecules. Herein, we present a three-step synthesis of threeand five-membered PAHs via a cross-coupling and subsequent electrophilic cyclization sequence (Table 1 ). This represents the first bottom-up $B N-P A H$ synthesis starting from a monocyclic 1,2-azaborinine.

The initial key step of our approach was a Suzuki-Miyaura cross-coupling of azaborinine nucleophile $\mathbf{1}$ with six different alkynylaryl halides, using slightly modified conditions from Liu et al. ${ }^{56}$ While 1 was synthesized over seven steps in $5.3 \%$ total yield, 56 the electrophiles were mostly prepared by electrophilic halogenations and subsequent, iodo-selective Sonogashira cross-coupling reactions with trimethylsilylacetylene.

bromo(trimethylsilylethynyl)benzene and -pyridine 10, three regioisomers of dibromobis(trimethylsilylethynyl)benzenes 11-13 were used as electrophilic components (Table 1). All Suzuki-Miyaura crosscoupling reactions were complete after $6 \mathrm{~h}$ at $80^{\circ} \mathrm{C}$ in a microwave reactor, giving biphenylyl or terphenylyl alkynes 14-19 in good yields (Table 1). A recurring by-product was the homo-coupled bis(azaborinine) $\mathbf{2 0}$, which we could isolate and characterize (Scheme 2). Subsequent deprotection of the TMSprotected alkynes with $\mathrm{KOH}$ furnished the corresponding alkynes, which were directly converted in an electrophilic ring closure by heating them with 30 mol\% platinum(II) chloride in toluene for 4 h. ${ }^{49}$ Without any exceptions, the main components were the desired products with newly formed sixmembered rings (Table 1). However, some syntheses suffered from the formation of side-products with equal molecular mass and very similar retardation factors, which explains the divergent yields. Both the formation of new five-membered rings via a competing 5-exo-dig cyclization and the formation of new six-membered rings via the azaborinine nitrogen atom are plausible mechanisms (see ESI).
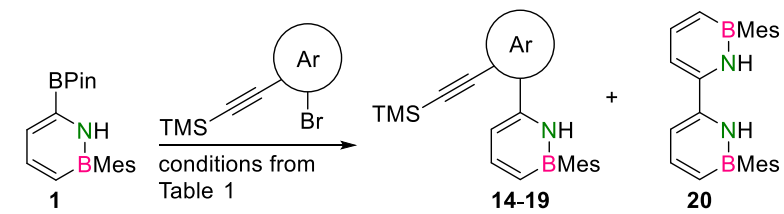

Scheme 2 Illustration of by-product 20, which arose in many Suzuki-Miyaura crosscoupling reactions involving azaborinine nucleophile 1 and different electrophiles 14-19.
In the subsequent discussion of the molecules' properties, we compare the newly synthesized BN-PAH1-6 with their $C C$ analogs. However, as the exact $C C$ counterparts have not been reported, the data of their unsubstituted analogs phenanthrene 21, benzo[ $h]$ quinoline naphtho[1,2-b]thiophene dibenz $[a, h]$ anthracene $\mathbf{2 5}$ and picene $\mathbf{2 6}$ are used.

All $B N$-PAHs were chemically stable and soluble in common organic solvents $\left(\mathrm{CHCl}_{3}, \mathrm{THF}\right.$, slightly in $n$-pentane and methanol), which can be attributed to the solubilizing $B N$ units, inducing strong dipole moments. The $B N$-PAHs were characterized by NMR, HR-MS, IR, UV/vis and PL spectroscopy.

For small BN-PAH1-3, melting points of $100-150{ }^{\circ} \mathrm{C}$ were measured. Large BN-PAH4 and BN-PAH5, containing anthracene units, did not melt but decomposed above $300^{\circ} \mathrm{C}$, in contrast to $C C$ analogs $\mathbf{2 4}$ and $\mathbf{2 5}$, whose melting points are below $300{ }^{\circ} \mathrm{C} .5^{57}$ The comparatively low melting point of BN-PAH6 $\left(<125^{\circ} \mathrm{C}\right)$ was presumably caused by the unfavorably oriented mesityl groups, which prevent intense overlapping of the PAH backbones by inducing steric repulsion, in contrast to BN-PAH4 and BN-PAH5 (see next paragraphs). Furthermore these values mirror the notably lower melting point of phenanthrene compared to anthracene. ${ }^{58}$

Single crystals suitable for X-ray diffraction analysis were obtained for BN-PAH1, 2, $\mathbf{4}$ and $\mathbf{5}$ by slow evaporation of the solvents (see Table 1 and ESI). BN-PAH4 crystallized with one molecule $\mathrm{CDCl}_{3}$ per asymmetric unit, which can be attributed to its cavity. The results showed significantly distorted mesitylgroups $\left(\phi_{\max }\right.$ between $61.7^{\circ}$ and $81.2^{\circ}$ ), while the backbones were almost planar with the highest torsion angle found in BN-PAH4 ( $\phi_{\max }=5.2^{\circ}$, due to slight proton-proton repulsion). Bond lengths in the azaborinine unit match reported values, showing a significant $B N$ double bond character. ${ }^{51}$

Except for BN-PAH1, which showed a herringbone packing arrangement with a plane to plane angle of $44.9^{\circ}$, all derivatives revealed parallel-displaced packing of the PAH scaffolds (see ESI). Low plane distances $(3.40-3.60 \AA$ ) support the presence of classical $\pi$ - $\pi$-interactions. As Hirshfeld surface analysis clarified, the dipolar $B N$ units were uninvolved in the packing formations of all derivatives, most likely due to their peripheral locations (see ESI). Likewise, the mesityl groups apparently did not impede stacking, different from a previously described $B N$-PAH with more central mesityl units. ${ }^{59}$ On the contrary, BN-PAH4 and BN-PAH5 showed large overlaps of the PAH scaffolds.

The electronic properties of the target molecules were analyzed by performing nucleus-independent chemical shift $(\mathrm{NICS})^{60}$ calculations at the MP2/cc-pVDZ level.61,62 The azaborinine rings were moderately aromatic, displaying NICS(0) values of -3.0 to $-3.4 \mathrm{ppm}$. All other rings were highly aromatic $(\operatorname{NICS}(0)=-7.0$ to $-12.1 \mathrm{ppm})$, in accordance with the common differences between anthracene and phenanthrene cores ${ }^{63}$ (see ESI). 
Table 2 Photophysical properties of BN-PAH1-6

\begin{tabular}{|c|c|c|c|c|c|c|c|c|}
\hline Compound & $\begin{array}{c}\lambda_{\text {abs }} \\
\left(\mathrm{CHCl}_{3}\right)[\mathrm{nm}]^{\mathrm{a}}\end{array}$ & $\begin{array}{c}\varepsilon \\
{\left[\mathrm{mol}^{-1} \mathrm{~L} \mathrm{~cm}^{-1}\right]}\end{array}$ & $\begin{array}{c}\lambda_{\text {lum }} \\
\left(\mathrm{CHCl}_{3}\right)[\mathrm{nm}]^{\mathrm{a}}\end{array}$ & $\begin{array}{l}\text { Stokes Shift } \\
\left(\mathrm{CHCl}_{3}\right)\left[\mathrm{cm}^{-1}\right]\end{array}$ & $\underset{\left(\mathrm{CHCl}_{3}\right)}{\Phi_{\text {lum }}}$ & $\begin{array}{c}\lambda_{\text {lum }} \\
\text { (solid) }[\mathrm{nm}]^{\mathrm{a}}\end{array}$ & $\begin{array}{l}\text { Stokes Shift } \\
\text { (solid) }\left[\mathrm{cm}^{-1}\right]\end{array}$ & $\begin{array}{l}\Phi_{\text {lum }} \\
\text { (solid) }\end{array}$ \\
\hline BN-PAH1 & $275,322,338,354$ & 50931 & $361, \mathbf{3 7 9}, 398$ & 548 & 0.40 & 368,409 & 1401 & 0.03 \\
\hline$B N-P A H 2$ & $258,317,331,347$ & 40303 & $356, \mathbf{3 7 2}$ & 729 & 0.09 & 378, 394 & 1323 & $<0.01$ \\
\hline BN-PAH3 & $\mathbf{2 8 3}, 331,348$ & 42583 & 389 & $\mathrm{~b}$ & 0.06 & 380 & 1774 & 0.05 \\
\hline BN-PAH4 & $317,365,384,406$ & 58811 & $423,451,480$ & 990 & 0.17 & 574 & 5943 & 0.06 \\
\hline BN-PAH5 & $316,378,399,422$ & 122343 & $427,456,486$ & 278 & 0.24 & $460,487,521$ & 1249 & 0.02 \\
\hline BN-PAH6 & $285, \mathbf{3 4 1}, 371,387$ & 51736 & $392,412,437$ & 330 & 0.16 & $399,417,441$ & $\mathrm{~b}$ & 0.02 \\
\hline
\end{tabular}

a Bold values represent intensity maxima. $\mathrm{c}=10^{-6}-10^{-4} \mathrm{~mol} \mathrm{~L}^{-1} .{ }^{\mathrm{b}}$ The highest energy PL band was not identified due to a lack of vibronic resolution.

The photophysical properties were determined by means of UV/vis absorption and PL spectroscopy (Table 2). Except for BN-PAH6, all compounds showed absorption spectra of similar shapes in solution (see ESI): One high energetic global maximum band was followed by three local maximum bands at lower energies (315 - $355 \mathrm{~nm}$ for small BN-PAH1-3, $365-425 \mathrm{~nm}$ for large BN-PAH4-5), representing vibrational sub-levels. For all derivatives, the molar extinction coefficients at the intensity maxima were particularly high.

CC analogs 21, 24, 25 and 26 revealed very similar spectra, though slightly hypsochromically shifted maxima and more closely adjoined bands. ${ }^{57,64}$

Except for $\mathbf{B N}$-PAH3, the emission spectra in solution resembled each other and consisted of three main bands and one or two less intense bands at high wavelengths (Fig. 1 and Table 2). While three-membered BN-PAH1-3 showed emission maxima between 355 and $400 \mathrm{~nm}$, the emission maxima of their five-membered congeners BN-PAH4-5 were located between 420 and $490 \mathrm{~nm}$, which demonstrates the powerful effect that the addition of rings to a small PAH structure can have. BN-PAH6 also exhibited five emission bands, albeit at higher energies $(390-440 \mathrm{~nm}$ ). The emission band of BN-PAH3 was significantly broadened with the loss of vibronic resolution. We assume that this arises from an increased dipole moment in its excited state geometry. This feature also makes BN-PAH3 slightly solvatochromic if compared to all other $B N$-PAHs (see ESI).

For all other $B N-P A H s$, the observed Stokes shifts were small $\left(278-990 \mathrm{~cm}^{-1}\right)$, suggesting small structural changes in the stiff backbone upon excitation. Along with the vibrationally wellresolved shapes of the spectra, this implies the presence of

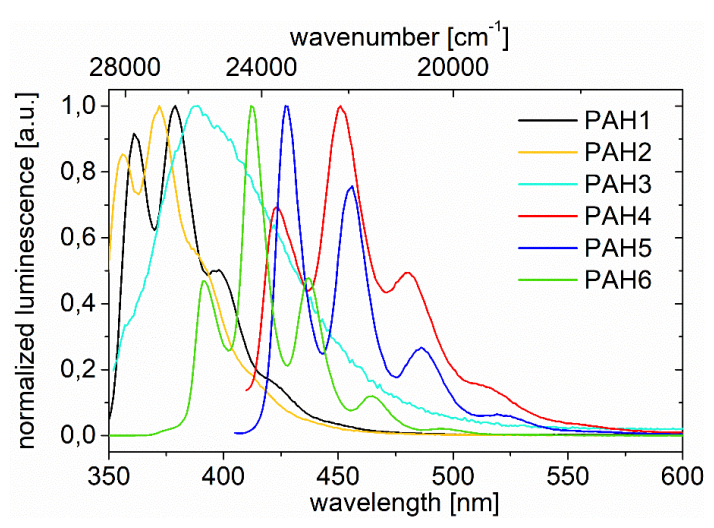

Fig. 1 Normalized PL spectra of BN-PAH1-6 in chloroform solution. rigid, delocalized structures. Our results approximately reflect reported spectra for $C C$ analogs $\mathbf{2 1},{ }^{65} \mathbf{2 3}^{66} \mathbf{2 5}^{67}$ and $\mathbf{2 6},{ }^{64}$ however these were shifted hypsochromically to BN-PAH1-6 by $13-40 \mathrm{~nm}$. Especially the large $B N$-PAHs almost exactly mirrored the spectral shapes of common PAHs like anthracene, ${ }^{68}$ which indicates that they behave like substituted PAHs rather than like PAHs, in which the heteroatoms predominate the electronic structures.

The PL quantum yield of $\mathbf{B N}$-PAH1 was good $\left(\Phi_{\text {lum }}=0.40\right)$, while the other three-membered PAHs showed low values ( $\left.\Phi_{\text {lum }}<0.10\right)$. Large BN-PAH4-6 displayed values of $\Phi_{\text {lum }}=0.16-0.24$. In contrast, $C C$ analogs $21\left(\Phi_{\text {lum }}=0.09\right)^{37}$ and $25\left(\Phi_{\text {lum }}=0.035\right)^{67}$ were significantly less emissive.

The emission bands in solid state were mostly comparable to these in solution, though broadened. Often, the emission curve mirrored the shape of the absorption curve, with Stokes shifts of typically $<2000 \mathrm{~cm}^{-1}$ and noticeable fine structuring. Most remarkably, the spectra of regioisomers BN-PAH4 and BN-PAH5, which reveal very similar emission spectra in solution (Fig. 1), differed dramatically in solid state (Fig. 2), giving rise to very different emission colors (Fig. 3). While BN-PAH5 showed a fine-structured spectrum with three main bands between 460 and $560 \mathrm{~nm}, \mathbf{B N}$-PAH4 exhibited a single broad band with a maximum of $574 \mathrm{~nm}$.
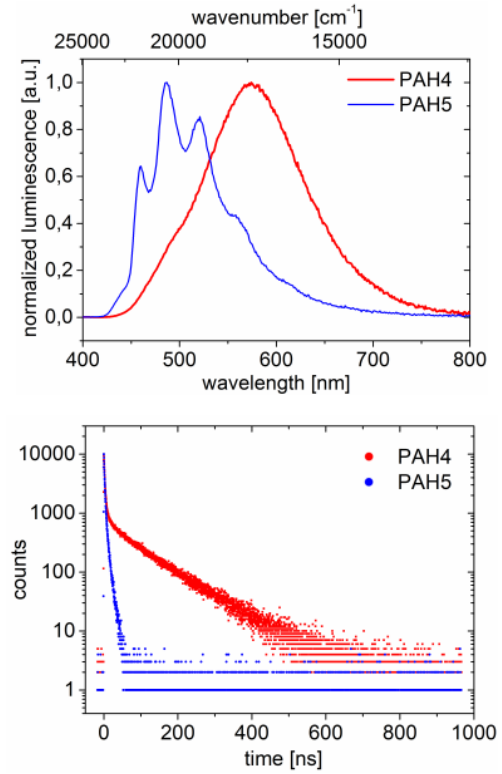

Fig. 2 Normalized PL spectra of BN-PAH4 and BN-PAH5 in solid state and corresponding PL lifetime curves. 


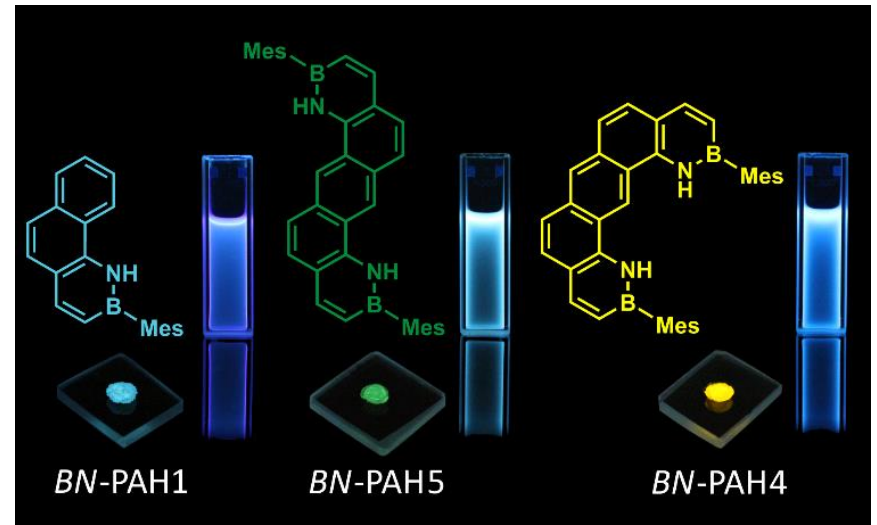

Fig. 3 Photographs of dissolved samples of $\mathbf{B N}$-PAH1, BN-PAH5 and $\mathbf{B N}$-PAH4 in glass cuvettes (solvent: chloroform) and in solid state on glass slides after dropcasting from highly concentrated DCM solutions. Samples were irradiated at $\lambda=365 \mathrm{~nm}$.

Furthermore, the Stokes shift increased from $1249 \mathrm{~cm}^{-1}$ in BN-PAH5 to $5943 \mathrm{~cm}^{-1}$ in BN-PAH4. It is likely that this particularity arises from the formation of excimers in the solid state. This is supported by PL lifetime measurements of BN-PAH4 that showed a second decay that was much slower than the first one (100 ns vs. $2.91 \mathrm{~ns}$ ), and the absence of finestructuring. In contrast, none of the other compounds displayed lifetimes $>10 \mathrm{~ns}$. The phenomenon of considerable extension of PL lifetimes in excimers has been reported for other PAHs, especially pyrene. ${ }^{69}$ The quantum yields in the solid state were generally low $\left(\Phi_{\text {lum }}<0.01-0.06\right)$, which indicates that the molecules undergo strong aggregation-caused quenching due to their close intermolecular $\pi-\pi$-interactions.

To improve our understanding of the measured emission spectra, we performed time-dependent Density Functional Theory (TD-DFT) 70 calculations at the B3LYP / cc-pVDZ level of theory. ${ }^{62,71-73}$ All calculated fluorescence wavelengths were in good agreement with the maximum intensities of the measurements, with deviations of $\lambda_{\max }$ between -31 and $+22 \mathrm{~nm}$ (see ESI). For large BN-PAH4-6, natural transition orbital (NTO) calculations revealed a $\pi-\pi^{*}$ character of the $S_{1}$ states, from which fluorescence takes place, with extensive delocalization of the orbitals over the PAH scaffold (Fig. 4).

\section{Conclusions}

In conclusion, we have developed a convergent synthetic method towards $B N$-PAHs via a cross-coupling and electrocyclization protocol. Besides the benefit of employing

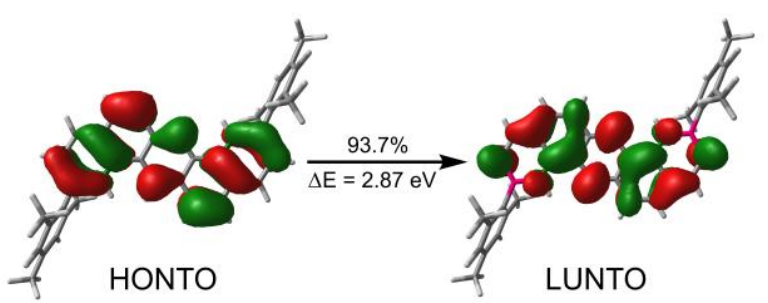

Fig. 4 Highest occupied (HONTO) and lowest unoccupied (LUNTO) NTO for the $\mathrm{S}_{1}$ state of BN-PAH5. the same nucleophilic 1,2-azaborinine precursor for all derivatives, this flexible approach allows the introduction of a broad scope of electrophilic cross-coupling partners and does not require substituted $\mathrm{PAH}$ precursors.

The optical measurements disclosed that all derivatives were emissive both in solution and in the solid state. The quantum yields in solution were low to moderate and comprised a broad range of values of $\Phi_{\text {lum }}=0.06-0.40$, however, these values were still superior compared to the $C C$ analogs. Due to aggregation-caused quenching, the quantum yields in the solid state were consistently low. As an unexpected attribute, BN-PAH4 revealed the presence of excimers in solid state. This additional intermolecular interaction induces a large bathochromic shift, compared to its regioisomers, and notably enhances the PL lifetime.

This dependency of the emission wavelength on the connectivity of the rings along with the potential of introducing substituents to expand the $\pi$-system ${ }^{37}$ could make our methodology the starting point for synthesizing a number of novel $B N$-PAHs with precisely tuned emission wavelengths in the future.

\section{Conflicts of interest}

There are no conflicts to declare.

\section{Acknowledgements}

A.S. and Y.A. thank the German Research Foundation (DFG) for the Emmy-Noether-Grant STA1195/2-1. N.B. and P.R. thank the DFG for partial funding under Germany's Excellence Strategy within the Cluster of Excellence PhoenixD (EXC 2122, Project ID 390833453) and the European Research Council (ERC) under the European Union's Horizon 2020 research and innovation programme (grant agreement No. 714429). We thank Philipp J. Gliese for his support in the optimization of the azaborinine precursor syntheses and Daniel Duvinage for his support in the cyclic voltammetry measurements.

\section{Notes and references}

1. A. J. Ashe and Fang, A Synthesis of Aromatic Five- and SixMembered B-N Heterocycles via Ring Closing Metathesis, Org. Lett., 2000, 2, 2089-2091.

2. P. G. Campbell, A. J. V. Marwitz and S.-Y. Liu, Recent Advances in Azaborine Chemistry, Angew. Chem. Int. Ed., 2012, 51, 6074-6092.

3. E. R. Abbey, L. N. Zakharov and S.-Y. Liu, Crystal Clear Structural Evidence for Electron Delocalization in 1,2 Dihydro-1,2-azaborines, J. Am. Chem. Soc., 2008, 130 7250-7252.

4. P. G. Campbell, E. R. Abbey, D. Neiner, D. J. Grant, D. A. Dixon and S.-Y. Liu, Resonance Stabilization Energy of 1,2Azaborines: A Quantitative Experimental Study by Reaction Calorimetry, J. Am. Chem. Soc., 2010, 132, 18048-18050. 
5. M. Baranac-Stojanović, Aromaticity and Stability of Azaborines, Chem. Eur. J., 2014, 20, 16558-16565.

6. R. Carion, V. Liégeois, B. Champagne, D. Bonifazi, S. Pelloni and P. Lazzeretti, On the Aromatic Character of 1,2-Dihydro-1,2-azaborine According to Magnetic Criteria, J. Phys. Chem. Lett., 2010, 1, 1563-1568.

7. A. M. Daly, C. Tanjaroon, A. J. V. Marwitz, S.-Y. Liu and S. G. Kukolich, Microwave Spectrum, Structural Parameters, and Quadrupole Coupling for 1,2-Dihydro-1,2-azaborine, J. Am. Chem. Soc., 2010, 132, 5501-5506.

8. M. J. D. Bosdet and W. E. Piers, B-N as a C-C substitute in aromatic systems, Can. J. Chem., 2009, 87, 8-29.

9. B. Thiedemann, P. J. Gliese, J. Hoffmann, P. G. Lawrence, F. D. Sönnichsen and A. Staubitz, High molecular weight poly(N-methyl-B-vinylazaborine) - a semi-inorganic B-N polystyrene analogue, Chem. Commun., 2017, 53, 72587261.

10. A. W. Baggett, F. Guo, B. Li, S.-Y. Liu and F. Jäkle, Regioregular Synthesis of Azaborine Oligomers and a Polymer with a syn Conformation Stabilized by $\mathrm{NH} \cdots \pi$ Interactions, Angew. Chem. Int. Ed., 2015, 54, 1119111195.

11. H. Lin, C. R. McConnell, B. Jilus, S.-Y. Liu and F. Jäkle, Changing up BN-Polystyrene: Effect of Substitution Pattern on the Free-Radical Polymerization and Polymer Properties, Macromolecules, 2019, 52, 4500-4509.

12. H. L. van de Wouw, J. Y. Lee and R. S. Klausen, Gram-scale free radical polymerization of an azaborine vinyl monomer, Chem. Commun., 2017, 53, 7262-7265.

13. H. L. van de Wouw, J. Y. Lee, E. C. Awuyah and R. S Klausen, A BN Aromatic Ring Strategy for Tunable Hydroxy Content in Polystyrene, Angew. Chem. Int. Ed., 2018, 57, 1673-1677.

14. H. L. van de Wouw and R. S. Klausen, BN Polystyrenes: Emerging Optical Materials and Versatile Intermediates, J. Org. Chem., 2019, 84, 1117-1125.

15. R. Rieger and K. Müllen, Forever young: polycyclic aromatic hydrocarbons as model cases for structural and optical studies, J. Phys. Org. Chem., 2010, 23, 315-325.

16. Y.-H. Chung, L. Sheng, X. Xing, L. Zheng, M. Bian, Z. Chen, L. Xiao and Q. Gong, A pure blue emitter (CIEy $\approx 0.08$ ) of chrysene derivative with high thermal stability for OLED, $J$. Mater. Chem. C, 2015, 3, 1794-1798.

17. S. W. Slayden and J. F. Liebman, The Energetics of Aromatic Hydrocarbons: An Experimental Thermochemical Perspective, Chem. Rev., 2001, 101, 1541-1566.

18. J. E. Anthony, Functionalized Acenes and Heteroacenes for Organic Electronics, Chem. Rev., 2006, 106, 50285048.

19. C. F. Matta and J. Hernández-Trujillo, Bonding in Polycyclic Aromatic Hydrocarbons in Terms of the Electron Density and of Electron Delocalization, J. Phys. Chem. A, 2003, 107, 7496-7504.

20. K. Balakrishnan, A. Datar, R. Oitker, H. Chen, J. Zuo and L. Zang, Nanobelt Self-Assembly from an Organic n-Type Semiconductor: Propoxyethyl-PTCDI, J. Am. Chem. Soc., 2005, 127, 10496-10497.

21. F. Liu, C. Tang, Q.-Q. Chen, F.-F. Shi, H.-B. Wu, L.-H. Xie, B. Peng, W. Wei, Y. Cao and W. Huang, Supramolecular $\pi-\pi$ Stacking Pyrene-Functioned Fluorenes: Toward Efficient Solution-Processable Small Molecule Blue and White
Organic Light Emitting Diodes, J. Phys. Chem. C, 2009, 113, 4641-4647.

22. A. M. v. d. Craats, J. M. Warman, A. Fechtenkötter, J. D. Brand, M. A. Harbison and K. Müllen, Record Charge Carrier Mobility in a Room-Temperature Discotic LiquidCrystalline Derivative of Hexabenzocoronene, Adv. Mater., 1999, 11, 1469-1472.

23. H.-Y. Oh, C. Lee and S. Lee, Efficient blue organic lightemitting diodes using newly-developed pyrene-based electron transport materials, Org. Electron., 2009, 10, 163-169.

24. Y. Li, T. Yu, W. Su, Y. Wang, Y. Zhao and H. Zhang, Polycyclic aromatic hydrocarbon-bridged coumarin derivatives for organic light-emitting devices, Arab. J. Chem., 2020, 13, 4126-4133.

25. E. Heyer and R. Ziessel, Mono-functionalized dibenzo[g,p]chrysenes for cascade energy transfer, Tetrahedron Lett., 2013, 54, 3388-3393.

26. Y. Liu, Q. Bai, J. Li, S. Zhang, C. Zhang, F. Lu, B. Yang and P. Lu, Efficient pyrene-imidazole derivatives for organic lightemitting diodes, RSC Adv., 2016, 6, 17239-17245.

27. S. Chidirala, H. Ulla, A. Valaboju, M. R. Kiran, M. E. Mohanty, M. N. Satyanarayan, G. Umesh, K. Bhanuprakash and V. J. Rao, Pyrene-Oxadiazoles for Organic Light-Emitting Diodes: Triplet to Singlet Energy Transfer and Role of Hole-Injection/Hole-Blocking Materials, J. Org. Chem., 2016, 81, 603-614.

28. E. Kozma, W. Mróz, F. Villafiorita-Monteleone, F. Galeotti, A. Andicsová-Eckstein, M. Catellani and C. Botta, Perylene diimide derivatives as red and deep red-emitters for fully solution processable OLEDs, RSC Adv., 2016, 6, 6117561179.

29. F. Zhang, Y. Ma, Y. Chi, H. Yu, Y. Li, T. Jiang, X. Wei and J. Shi, Self-assembly, optical and electrical properties of perylene diimide dyes bearing unsymmetrical substituents at bay position, Sci. Rep., 2018, 8, 8208.

30. T. M. Figueira-Duarte and K. Müllen, Pyrene-Based Materials for Organic Electronics, Chem. Rev., 2011, 111, 7260-7314.

31. M. Chen, L. Yan, Y. Zhao, I. Murtaza, H. Meng and W. Huang, Anthracene-based semiconductors for organic field-effect transistors, J. Mater. Chem. C, 2018, 6, 74167444.

32. J. S. A. Ishibashi, J. L. Marshall, A. Mazière, G. J. Lovinger, B. Li, L. N. Zakharov, A. Dargelos, A. Graciaa, A. Chrostowska and S.-Y. Liu, Two BN Isosteres of Anthracene: Synthesis and Characterization, J. Am. Chem. Soc., 2014, 136, 15414-15421.

33. X.-Y. Wang, F.-D. Zhuang, J.-Y. Wang and J. Pei, Incorporation of polycyclic azaborine compounds into polythiophene-type conjugated polymers for organic field-effect transistors, Chem. Commun., 2015, 51, 1753217535.

34. X.-Y. Wang, H.-R. Lin, T. Lei, D.-C. Yang, F.-D. Zhuang, J.-Y. Wang, S.-C. Yuan and J. Pei, Azaborine Compounds for Organic Field-Effect Transistors: Efficient Synthesis, Remarkable Stability, and BN Dipole Interactions, Angew. Chem. Int. Ed., 2013, 52, 3117-3120.

35. F.-D. Zhuang, Z.-H. Sun, Z.-F. Yao, Q.-R. Chen, Z. Huang, J.H. Yang, J.-Y. Wang and J. Pei, BN-Embedded Tetrabenzopentacene: A Pentacene Derivative with 
Improved Stability, Angew. Chem. Int. Ed., 2019, 58, 10708-10712.

36. E. R. Abbey, L. N. Zakharov and S.-Y. Liu, Boron in Disguise: The Parent "Fused" BN Indole, J. Am. Chem. Soc., 2011, 133, 11508-11511.

37. A. Abengózar, D. Sucunza, P. García-García, D. Sampedro, A. Pérez-Redondo and J. J. Vaquero, A New Member of the BN-Phenanthrene Family: Understanding the Role of the B-N Bond Position, J. Org. Chem., 2019, 84, 71137122

C. J. Saint-Louis, L. L. Magill, J. A. Wilson, A. R. Schroeder, S. E. Harrell, N. S. Jackson, J. A. Trindell, S. Kim, A. R. Fisch, L. Munro, V. J. Catalano, C. E. Webster, P. P. Vaughan, K. S. Molek, A. K. Schrock and M. T. Huggins, The Synthesis and Characterization of Highly Fluorescent Polycyclic Azaborine Chromophores, J. Org. Chem., 2016, 81, 10955 10963.

39. T. Hatakeyama, S. Hashimoto, S. Seki and M. Nakamura Synthesis of BN-Fused Polycyclic Aromatics via Tandem Intramolecular Electrophilic Arene Borylation, J. Am. Chem. Soc., 2011, 133, 18614-18617.

40. X. Wang, F. Zhang, J. Liu, R. Tang, Y. Fu, D. Wu, Q. Xu, X. Zhuang, G. He and X. Feng, Ladder-Type BN-Embedded Heteroacenes with Blue Emission, Org. Lett., 2013, 15, 5714-5717.

41. G. Li, Y. Zhao, J. Li, J. Cao, J. Zhu, X. W. Sun and Q. Zhang, Synthesis, Characterization, Physical Properties, and OLED Application of Single BN-Fused Perylene Diimide, J. Org. Chem., 2015, 80, 196-203.

42. M. Lepeltier, O. Lukoyanova, A. Jacobson, S. Jeeva and D. F. Perepichka, New azaborine-thiophene heteroacenes, Chem. Commun., 2010, 46, 7007-7009.

43. S. R. Wisniewski, C. L. Guenther, O. A. Argintaru and G. A. Molander, A Convergent, Modular Approach to Functionalized 2,1-Borazaronaphthalenes from 2Aminostyrenes and Potassium Organotrifluoroborates, $J$. Org. Chem., 2014, 79, 365-378. C. Zhang, BN-Phenanthrenes: Synthesis, Reactivity, and Optical Properties, Org. Lett., 2019, 21, 3476-3480.

45. A. Mazzanti, M. Boffa, E. Marotta and M. Mancinelli, Axial Chirality at the Boron-Carbon Bond: Synthesis, Stereodynamic Analysis, and Atropisomeric Resolution of 6-Aryl-5,6-dihydrodibenzo[c,e][1,2]azaborinines, J. Org. Chem., 2019, 84, 12253-12258.

46. S. Hashimoto, T. Ikuta, K. Shiren, S. Nakatsuka, J. Ni, M. Nakamura and T. Hatakeyama, Triplet-Energy Control of Polycyclic Aromatic Hydrocarbons by BN Replacement: Development of Ambipolar Host Materials for Phosphorescent Organic Light-Emitting Diodes, Chem. Mater., 2014, 26, 6265-6271.

47. A. Abengózar, P. García-García, D. Sucunza, A. PérezRedondo and J. J. Vaquero, Synthesis of functionalized helical BN-benzo[c]phenanthrenes, Chem. Commun., 2018, 54, 2467-2470.

48. X. Fang, H. Yang, J. W. Kampf, M. M. Banaszak Holl and A. J. Ashe, Syntheses of Ring-Fused B-N Heteroaromatic Compounds, Organometallics, 2006, 25, 513-518.

49. M. J. D. Bosdet, C. A. Jaska, W. E. Piers, T. S. Sorensen and M. Parvez, Blue Fluorescent 4a-Aza-4bboraphenanthrenes, Org. Lett., 2007, 9, 1395-1398.
50. A. Fürstner and V. Mamane, Flexible Synthesis of Phenanthrenes by a $\mathrm{PtCl}_{2}$-Catalyzed Cycloisomerization Reaction, J. Org. Chem., 2002, 67, 6264-6267.

51. L. Zi, J. Zhang, C. Li, Y. Qu, B. Zhen, X. Liu and L. Zhang, Synthesis, Properties, and Reactivity of Bis-BN Phenanthrenes: Stepwise Bromination of the Main Scaffold, Org. Lett., 2020, 22, 1499-1503. M. J. D. Bosdet, W. E. Piers, T. S. Sorensen and M. Parvez, 10a-Aza-10b-borapyrenes: Heterocyclic Analogues of Pyrene with Internalized BN Moieties, Angew. Chem. Int. Ed., 2007, 46, 4940-4943.

53. J. M. Casas-Solvas, J. D. Howgego and A. P. Davis, Synthesis of substituted pyrenes by indirect methods, Org. Biomol. Chem., 2014, 12, 212-232.

54. S. Duan, J. Turk, J. Speigle, J. Corbin, J. Masnovi and R. J. Baker, Halogenations of Anthracenes and Dibenz [a,c]anthracene with N-Bromosuccinimide and NChlorosuccinimide, J. Org. Chem., 2000, 65, 3005-3009.

55. P. H. Gore, Abnormal Substitution Reactions of Anthracene and Phenanthrene, J. Org. Chem., 1957, 22, 135-138.

56. A. W. Baggett, M. Vasiliu, B. Li, D. A. Dixon and S.-Y. Liu, Late-Stage Functionalization of 1,2-Dihydro-1,2azaborines via Regioselective Iridium-Catalyzed $\mathrm{C}-\mathrm{H}$ Borylation: The Development of a New N,N-Bidentate Ligand Scaffold, J. Am. Chem. Soc., 2015, 137, 5536-5541.

57. Photoelectric Spectrometry Group England Staff, UV Atlas of Organic Compounds, Springer, Boston, 1967.

58. J. L. Goldfarb and I. Külaots, Melting points and enthalpies of fusion of anthracene and its heteroatomic counterparts, J. Therm. Anal. Calorim., 2010, 102, 1063.

59. T. Agou, J. Kobayashi and T. Kawashima, Syntheses, Structure, and Optical Properties of Ladder-Type Fused Azaborines, Org. Lett., 2006, 8, 2241-2244.

60. P. v. R. Schleyer, C. Maerker, A. Dransfeld, H. Jiao and N. J. R. van Eikema Hommes, Nucleus-Independent Chemical Shifts: A Simple and Efficient Aromaticity Probe, J. Am. Chem. Soc., 1996, 118, 6317-6318.

61. C. Møller and M. S. Plesset, Note on an Approximation Treatment for Many-Electron Systems, Phys. Rev., 1934, 46, 618-622.

62. T. H. Dunning Jr., Gaussian basis sets for use in correlated molecular calculations. I. The atoms boron through neon and hydrogen, J. Chem. Phys., 1989, 90, 1007-1023.

63. J. Poater, M. Duran and M. Solà, Aromaticity Determines the Relative Stability of Kinked vs. Straight Topologies in Polycyclic Aromatic Hydrocarbons, Front. Chem., 2018, 6.

64. A. Verdelli and A. Girlando, Vibronic structure of picene electronic transitions, Chem. Phys. Lett., 2014, 591, 47-51.

65. X.-Y. Wang, J.-Y. Wang and J. Pei, BN Heterosuperbenzenes: Synthesis and Properties, Chem. Eur. J., 2015, 21, 3528-3539.

66. M. Norek, J. Dresner and J. Prochorow, Spectroscopy and Photophysics of Monoazaphenanthrenes I. Absorption and Fluorescence Spectra of Phenanthridine and 7,8Benzoquinoline, Acta Phys. Pol. A, 2002, 104.

67. R. Umeda, S. Miyake and Y. Nishiyama, Synthesis of Dibenz[a,h]anthracenes by Pd-Catalyzed Intramolecular Double-cyclization of (Z,Z)-p-Styrylstilbenes, Chem. Lett., 2012, 41, 215-217.

68. K. Sudha, S. Sundharamurthi, S. Karthikaikumar, K. Abinaya and P. Kalimuthu, Switching of Förster to Dexter 
Mechanism of Short-Range Energy Transfer in mesoAnthrylporphyrin, J. Phys. Chem. C, 2017, 121, 5941-5948.

69. R. Katoh, S. Sinha, S. Murata and M. Tachiya, Origin of the stabilization energy of perylene excimer as studied by fluorescence and near-IR transient absorption spectroscopy, J. Photochem. Photobiol. A, 2001, 145, 2334.

70. R. Bauernschmitt and R. Ahlrichs, Treatment of electronic excitations within the adiabatic approximation of time dependent density functional theory, Chem. Phys. Lett., 1996, 256, 454-464.

71. A. D. Becke, Density-functional exchange-energy approximation with correct asymptotic behavior, Phys. Rev. A, 1988, 38, 3098-3100.

72. C. Lee, W. Yang and R. G. Parr, Development of the ColleSalvetti correlation-energy formula into a functional of the electron density, Phys. Rev. B, 1988, 37, 785-789.

73. A. D. Becke, A new mixing of Hartree-Fock and local density-functional theories, J. Chem. Phys., 1993, 98, 1372-1377. 